Lamia T Rejab

BDS, MSc (Asst. Prof.)

Oday A Al-Abbod

BDS, HDD

\section{Efficacy of Three Denture Cleansers on Candida-Related Denture Stomatitis}

\author{
Department of Prosthetic Dentistry \\ College of Dentistry, University of Mosul
}

Health Directorate. Ministry of Health

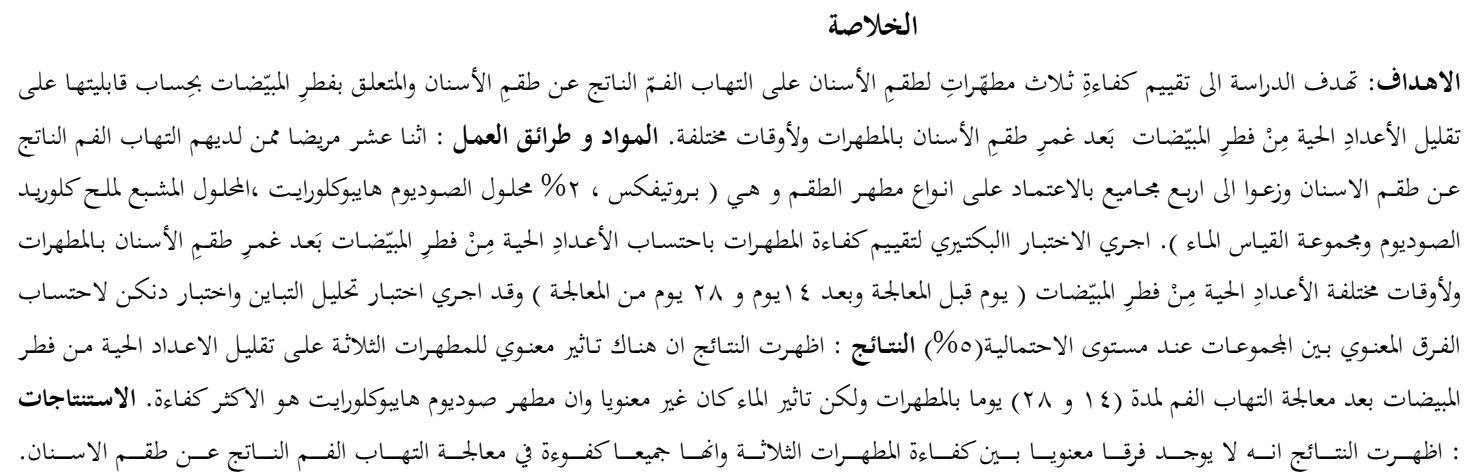

\begin{abstract}
Aim: The aim of the study is to evaluate the efficacy of three dentures cleanser on Candida related denture stomatitis through assessing their ability to reduce the number of colony forming unit (CFU) of Candida on palate of the patient for different times. Materials and methods: Group of 12 patients who have denture stomatitis were divided into four groups according to the type of denture cleaners (Protefix, sodium hypochlorite solution $0.02 \%$, saturated sodium chloride salt solution and control water). The microbiological examination was done to determine the efficacy of the cleansers that used by assessing the number of (CFU) at different times (day before treatment and after 14, 28days of treatment). The data were statistically analyzed, (ANOVA) followed by Duncan's multiple Range test to assess the significant difference between the groups at $P \leq 0.05$. Results: The results showed that there was a significant effect of three cleansers on reducing number of (CFU) of Candida species in the treatment of denture stomatitis after 14 and 28 days of treatment, but it was not significant for control water group. Sodium hypochlorite showed the highest efficacy. Conclusions: Result showed that there was no significant difference in the efficacy between the three cleansers indicating that all cleansers are effective in the treatment of denture stomatitis .
\end{abstract}

Key words: Denture cleaners, Candida, Stomatitis

Rejab LT, Al-Abbod OA. Efficacy of Three Denture Cleansers on Candida-Related Denture Stomatitis. Al-Rafidain Dent J. 2013; 13(2): 235-240.

Received: 15/12/2011 Sent to Referees: 18/12/2011 Accepted for Publication: 15/2/2012

\section{INTRODUCTION}

Acrylic resin is the most commonly used material for denture bases construction. $^{(1,2)}$ Denture stomatitis is one of the oral infections associated to the use of dentures. It is a chronic disease characterized by either localized or generalized inflammation or inflammatory papillary hyperplasia that may affect patients wearing complete or partial removable prostheses in one or both dental arches. ${ }^{(3,4)}$

Candida is a significant opportunistic pathogen of humans and is a major cause of denture stomatitis, an inflammation of tissues underlying dentures. Adherence is critical to the pathology of Candida, serving as a first step of infection for many microorganisms. In healthy mouth saliva flows and scraping by the tongue limit the accumulation of microorganisms. Prostheses impair this flushing, facilitating establishment of a focal infection by retention of Candida close to the basal seat. ${ }^{(5,6)}$ The disinfection of the prosthesis is recommended as prophylactic treatment and necessary for patients with high risk of 
stomatitis. ${ }^{(7,8)}$

The aim of the study is to evaluate the efficacy of three denture cleansers on Candida related denture stomatitis through assessing their ability to reduce the number of colony forming unit (CFU) of Candida on palate of the patient with denture stomatitis for different times (day before treatment and after 14, 28days of treatment).

\section{MATERIALS AND METHODS}

\section{Patients selection and Data Collection}

The patients enrolled in the current study have complete denture with conventional heat cured acrylic resin denture base material for more than 2 years, attending the Department of Prosthetic Dentistry, Mosul University. All the subjects underwent a routine dental checkup . A total of 156 patients, 50 patients were chosen (who do not have the exclusion criteria). The group consisted of 30 males and 20 females with age vary between (43years 75years). The exclusion criteria were: (1) Subjects taking antifungal agents or antiseptic mouthwashes.(2) Subjects taking medication known to predispose them to oral candidiosis, such as antibiotics or steroid therapy. (3) Subjects with a medical history of any disease or medical condition that predisposed them to oral candidiosis or promoted subjects oral carriage of Candida species. ${ }^{(9)}$

\section{Clinical Examination}

The oral mucosa covered by the maxillary complete denture was examined to determine and diagnose denture stomatitis. Denture stomatitis (denture sore mouth) is a form of erythematous candidiasis in which the diffuse redness of the mucosa corresponds to the area covered by the denture, it most diverts on the palate and may occur in acute or chronic form. It is characterized by pin-point hyperemia, diffuse erythema or granular inflammation of the denture-bearing areas. ${ }^{(10,11)}$

\section{Microbiological Examination}

A cotton swab was taken from the posterior mid-palatal part of the palatal mucosa of the patients. ${ }^{(9,12)}$ Then the swab placed in a screw capped bottle containing $(4.5 \mathrm{ml})$ of nutrient broth (Hemadia laboratorie ) as a transparent medium. The broth was diluted up to $10^{-4}$ by serial dilution , and $0.1 \mathrm{ml}$ of diluted broth was spread over two of Sabouraud's dextrose agar Petri dish (Oxoid/England) and incubated for $\left(48 \mathrm{hrs}\right.$ at $\left.37^{\circ} \mathrm{C}\right)$ in incubator( Fisher Scientific / Russia) and counted as (CFUs/ml) for the viable Candida. ${ }^{(13,14)}$

Identification of Candida was performed by the following diagnostic laboratory tests: (Culture characteristics): On Sabouraud' Dextrose Agar medium within (24-48) hrs at $37^{\circ} \mathrm{C}$, Candida species produce soft creamy colored colonies with a yeast odor. ${ }^{(13,14)}$ (Figure 1).

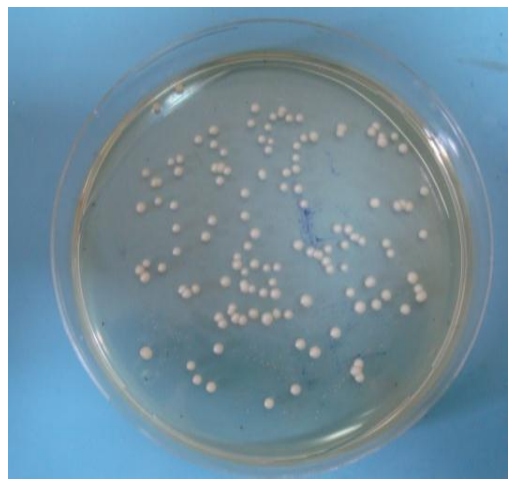

Figure (1):Colony Morphology of Candida

The smears obtained from the culture of patient's specimens were examined by light microscopic ( Lomo/Micmed/Russia) using crystal violet staining; the Candida species took gram positive stain. Microscopically it appeared as spherical to oval budding cells $(3-6 \mathrm{m \mu})$; the yeast or the blastospore form ${ }^{(15)}$ (Figure 2) . 


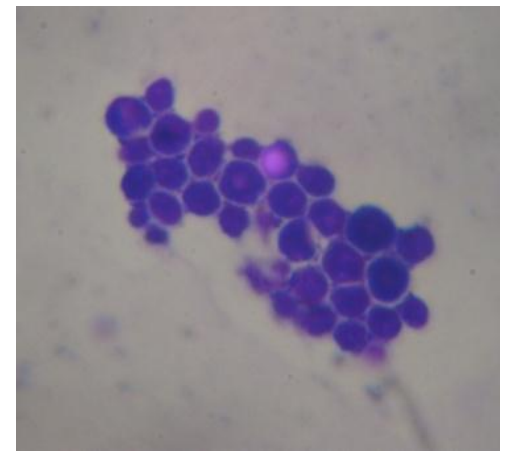

Figure (2): Candida under light microscope

Efficacy of Three Types of Denture Cleansers on Candida Related Denture Stomatitis

Group of 12 patients from 50 patients that chose of denture stomatitis were determined in the clinical examination. Patients were randomly divided into four groups according to the type of denture cleaners. Each group of three patients; first group, their denture soaked in Protefix/Germany (its $\mathrm{pH}$ is 7.49) which prepared according to the manufacturer's instruction. Second group soaked in sodium hypochlorite solution $0.02 \%$ (Clorox/Saudi Arabia ). ${ }^{(16,17)}$ Third group soaked in saturated salt solution $40 \mathrm{gm} / \mathrm{ml}$ Sodium chloride (without iodine) /Iraq. ${ }^{(18,19)}$ Fourth group as control group dentures were soaked in water. Dentures were soaked in cleaning solutions overnight on each day of the study periods (8 hours). The microbiological examination was done by the same way to determines the efficacy of the cleanser that used according to (the number of colony forming unit at each time). The efficacy of denture cleanser agents is assessed in reducing the number of microorganisms on palate of the patients at three different times (day before treatment and after 14, 28 days of treatment).

The data were statistically analyzed including; Descriptive statistic to show the mean and standard deviation. Analysis of variance (ANOVA) followed by Duncan's multiple Range test to assess the significant difference between the groups at $P \leq 0.05$.

\section{RESULTS}

In this study, the mean number of CFUs of microorganisms on the palatal mucosa for the different cleansers for three different times are shown in Tables (1).

Table (1): The mean CFUs of Candida on the Palatal mucosa for patients used different cleanser before treatment and after 14 and after 28 days of treatment.

\begin{tabular}{ccccc}
\hline Cleansers & Period & No. & Mean & $\mathbf{\pm}$ SD \\
\hline Saturated Salt Solution & Before treatment & 3 & 500.0 & 173.20 \\
& 14 Days & 3 & 16.67 & 5.77 \\
28 Days & 3 & 0.00 & 0.000 \\
Sodium Hypochlorite & Before treatment & 3 & 416.6 & 175.59 \\
$\mathbf{0 . 0 2 \%}$ & 14 Days & 3 & 10.0 & 0.000 \\
& 28 Days & 3 & 0.00 & 0.000 \\
Protefix & Before treatment & 3 & 333.3 & 57.73 \\
& 14 Days & 3 & 123.3 & 92.91 \\
Control & 28 Days & 3 & 3.3 & 5.77 \\
Water & Before treatment & 3 & 400.0 & 132.28 \\
& 14 Days & 3 & 346.6 & 100.16 \\
& 28 Days & 3 & 363.3 & 125.03 \\
\hline
\end{tabular}

No. Number of samples 
The result showed that sodium hypochlorite $0.02 \%$ has the highest efficacy in reduce number of CFUs after 14 and 28 days of treatment, while water group has the least effect. One way analysis of vari- ance (Table 2) shows that there is a significant difference on the CFUs of Candida between all cleansers after 14 and 28 days of treatment .

Table (2): Analysis of variance (ANOVA) among different cleansers for the mean of CFUs of Candida taken from palatal mucosa of the patients

\begin{tabular}{cccccc}
\hline Before treatment & Sum of Squares & D.F. & Mean Square & F-value & $\boldsymbol{p}$-value \\
\hline Between Groups & 42291.667 & 3 & 14097.22 & 00.690 & 0.853 \\
Within Groups & 163333.33 & 8 & 20416.66 & & \\
Total & 205625.00 & 11 & & & \\
\hline $\begin{array}{c}\text { 14 Days after treat- } \\
\text { ment }\end{array}$ & Sum of Squares & D.F. & Mean Square & F-value & $* \boldsymbol{p}$-value \\
$\begin{array}{c}\text { Between Groups } \\
\text { Within Groups }\end{array}$ & 222291.66 & 3 & 74097.22 & 15.850 & 0.001 \\
Total & 37400.00 & 8 & 4675.00 & & \\
\hline 28 Days after treat- & Sum of Squares & D.F. & Mean Square & F-value & $* \boldsymbol{p}$-value \\
ment & & & & \\
Between Groups & 255233.33 & 3 & 98411.11 & 25.126 & 0.000 \\
Within Groups & 31333.33 & 8 & 3916.66 & & \\
\hline Total & 326566.66 & 11 & & & \\
\hline$* P$-value: Means are highly significant different at $P \leq 0.01$ & DF: Degree of freedom &
\end{tabular}

The Duncan's Multiple Range Test for the effect of cleansers on the Candidal CFUs (taken from the Palate of the pa- tients) after 14 and after 28 days of treatment (Figure 3).

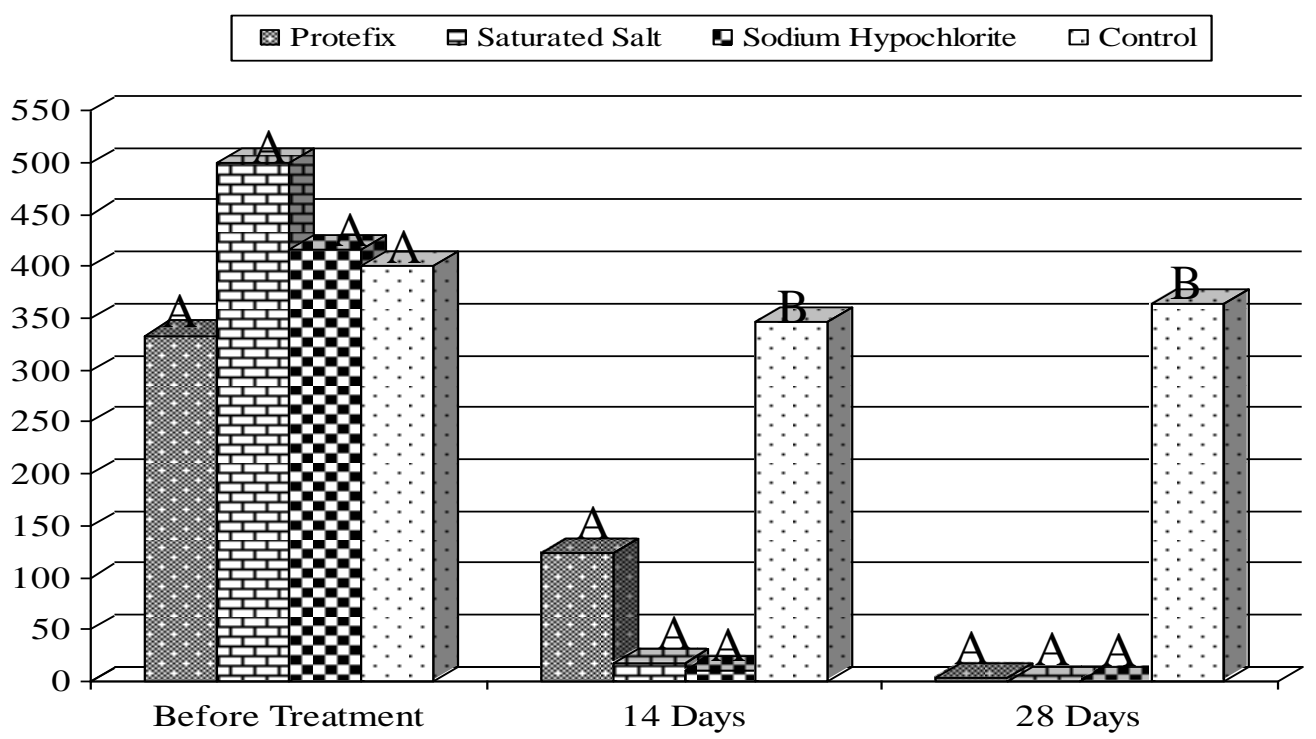

Means with the same litter have no statistically significant difference at $\mathrm{P} \leq 0.05$

Figure (3) : Duncan's Multiple Range Test (DMRT) for the effect of different cleansers on the Candidal CFUs (taken from the palate of the patients) after 14, 28 days of treatment.

The result revealed that there is no significant difference between the effect of three denture cleaners on CFUs by Candida after 14 and 28 days of treatment, but there is a significant difference be- tween the three cleaners and that of control group (water).The three agents that were used by the patients in this study are significant in reducing the No. of CFUs of Candida species. The application of 
Protefix (commercial denture cleanser) modulates the candidal adherence to denture acrylic and affect the colonization rate of Candida on the surfaces of dentures and palatal mucosa, this agrees with Nalbant $e t$ al. ${ }^{(9)}$

Sodium hypochlorite is one of the earliest and most widely used disinfectant. It can be a bactericide and fungicide, because it acts directly on the organic matrix of the plaque, resulting in the dissolution of the polymer's structure, probably because of oxidation of the protean component or significantly reducing the adhesion of most Candida sp. to the oral epithelial cells ${ }^{(17)}$. These characteristics allow the hypochlorite to reduce Candida sp. adhesive ability, but it does not work as an anti invasive barrier, as it is not able to prevent the production of proteinases by the Candida $\mathrm{sp}$. These findings show that sodium hypochlorite acts as an anti-fungi agent if used as a solution to submerge dentures in cases of denture stomatitis. ${ }^{(20)}$

Sodium chloride is commonly called as salt, common salt, table salt. It is an ionic compound having the structural formula $\mathrm{NaCl}$. The most important property of sodium chloride is its inflammability. Many microorganisms cannot live in excess salty environment, water is drawn out of the cells by the process of osmosis. For this reason, salt is used for disinfecting. ${ }^{(21,22)}$

The results showed that there is a significant difference between saturated salt solution and distilled water as Protefix and Sodium hypochlorite $0.02 \%$, therefore, it is considered as effective method in disinfection of denture contaminated with Candida species, this agrees with AlSumaidae. ${ }^{(19)}$

This study showed that disinfection of the denture is a successful method of treatment, and the denture is the source of the infection and no other treatment necessary, and this agrees with Webb et al. ${ }^{(16)}$

\section{CONCLUSIONS}

The results revealed that the three cleansers were have significant effect in reducing the No. of CFUs of Candida species. Also, the result showed that there is no significant difference in treatment efficacy between the three cleansers indicat- ing that all cleansers were effective in the treatment of denture stomatitis.

\section{REFERENCES}

1. Peyton FA. History of resins in dentistry. Dent Clin North Am. 1975;19(2):211-222.

2. Craig RG. Restorative Dental materials. 10th ed. The C.V. Mosby Co. 1997;. Ch. 19; pp. 500-524.

3. Webb BC, Thomas CJ, Willcox MDP, Harty DWS, Knox KW. Candida-associated denture stomatitis: Aetiology and management: A review. Part 1. Factors influencing distribution of candida species in the oral cavity. Aust Dent J. 1998; 43(4):4550.

4. Sesma N, Lagana DC, Morimoto S, Carlos G. Effect of Denture Surface Glazing on Denture Plaque Formation. Braz Dent J. 2005; 16(2): 129-134.

5. Rodriguez LO, Minah GH, Driscoll CF. Candida albicans colonization of surface sealed interim soft liners. $J$ Prosthet. (2000); 9: 184-188.

6. Zaremba ML, Daniluk TD, Cylwik $\mathrm{RD}$. Incidence rate of Candida species in the oral cavity of middle-aged and elderly subjects. Advances Med Sci; 2006; 51(1):233-263.

7. Mahonen K, Virtanen K, Larmas M. The effect of prosthesis disinfection on salivary microbial levels. J Oral Rehab.1998; 25:304-310.

8. Daniluk T, Fiedoruk K, Ściepuk M, . Aerobic bacteria in the oral cavity of patients woth removable dentures. Advances Med Sci. 2006 b; 51(1):8690.

9. Nalbant AD, Kalkanci A, Filiz B, Kustimur S. Effectiveness of Different Cleaning Agents against the Colonization of Candida spp and the in Vitro Detection of the Adherence of These Yeast Cells to Denture Acrylic Surfaces. Yonsei Med J. 2008; 49(4):647 - 654.

10. Aylin B, Robert W, Paul SW. Use of microwave energy to disinfect a longterm soft lining material contaminated with Candida albicans or Staphylo- 
coccus aureus. J Prosthet Dent .1998; 79:454-458.

11. Yilmaz HH, Aydin U, Ipek C. Is Denture Stomatitis related with denture hygiene?. Gulhane Tip Dergisi. 2002; 44(4): $412-414$.

12. Gornitsky M, Paradis I, Landaverde G, Malo A. A Clinical and Microbiological Evaluation of Denture Cleansers for Geriatric Patients in LongTerm Care Institutions. J Can Dent Assoc. 2002; 68(1):39-45.

13. Cruickshank R, Duguid JP, Marmion BP, Swain RHA. Medical microbiology: the practice of medical microbiology, bacteriology of water, milk, food, air. 12th ed. 1975; 277-278.

14. Hardy S.P. Human microbiology .Taylor \&Francis Inc. NY,USA. 2002; P 71.

15. Willey SJ, Rached RN, Rosalen PL, Cury AAD. Effects of Nystatin, Fluconazole and Propolis on Poly(Methyl Methacrylate) Resin Surface. Braz Dent J. 2008; 19(3): 190-196.

16. Webb BC, Thomas CJ, Whittle T. A 2-year study of Candida-associated denture stomatitis treatment in aged care subjects. Gerodontology . 2005; 22: 168-176.

17. Falah TA, Jafari AA, Lotfi K . Comparison of the Effectiveness of Sodi- um Hypochlorite and Dentamize Tablet for Denture Disinfection World. $J$ Med Sci. 2008; 3 (1): 10-14.

18. Al-Aubadi S M. New denture cleansers (comparative study). M.Sc Thesis. College of dentistry. University of Mosul. Iraq. 2007.

19. Al-Sumaidae RRA. The effect of natural products on disinfection and some physical properties of wax and acrylic denture base materials. M.Sc Thesis. College of dentistry. University of Mosul. Iraq. 2008.

20. Barnabe W, Mendonc A T, Pimenta FC, Pegoraro LF. Efficacy of sodium hypochlorite and coconut soap used as disinfecting agents in the reduction of denture stomatitis, Streptococcus mutants and Candida albicans. $J$ of Oral Rehabil. 2004; 31: 453-459.

21. Hiromasa K, Kouichi S,Shinichi M. Bactericidal activity of electrolyzed acid water from solution containing sodium chloride at low concentration, in comparison with that at high concentration. J Microl Meth . 2002;49: 285-293.

22. Somani SB ,Ingole NW, Kulkarni NS. Disinfection of water by using sodium chloride $(\mathrm{NaCl})$ and sodium hypochlorite (NaOCl). JERS. 2011;.II (IV) $40-43$. 